Indo Global Journal of Pharmaceutical Sciences, 2015; 5(3): 210-215

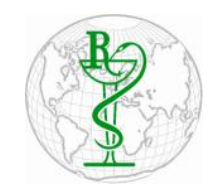

INDO GLOBAL JOURNAL OF

PHARMACEUTICAL SCIENCES

ISSN 2249- 1023

\title{
Histopathological Effects of Duovir-N on the Cerebellum of Wistar Rats
}

\author{
Peter $\mathrm{AI}^{1 *}$, Igiri $\mathrm{AO}^{2}$ \\ ${ }^{1}$ Department of Anatomy, Faculty of Basic Medical Sciences, University of Uyo, Nigeria \\ ${ }^{2}$ Department of Anatomy, Faculty of Basic Medical Sciences, University of Calabar, Nigeria
}

\begin{abstract}
Address for Correspondance Peter AI, aniekanpeter@un iuyo.edu.ng

\section{Keywords}

Histopathological

; Duovir-N;

Cerebellum;

Human

Immunodeficienc

y Virus.

ABSTRACT: DouvirR-N is a combination of three drugs (lamivudine, zidovudine and nevirapine) used for pre-exposure prophylaxis and management of Human Immunodeficiency Virus (HIV) infection in subSaharan Africa. The objective of this research work was to investigate the potential harmful effects of this drug on the histology of cerebellum of Wistar rats. Twenty male Wistar rats were used for this study. The rats were divided into 2 groups of 10 rats each. Group A served as the control, while group B were treated with $9.28 \mathrm{mg} / \mathrm{kg}$ of Duovir-N twice daily for 30 days. After the duration of drug administration, the rats were sacrificed using the chloroform inhalation method and their cerebellum harvested, processed and stained using haematoxylin and eosin, silver impregnation method, paraffin impregnated Glial Fibribular Acidic protein (GFAP), Neuron specific Enolase(NSE), and neurofillament(NF), immunochemistry methods. Stained slides were viewed under a light microscope. Results obtained showed that the cerebellum of Groups B in H\&E and silver stains was affected with severe shrinkage and distortion of the Purkinje cells, when compared with the control group. GFAP, NSE and NF test showed increased expression of GFAP, NSE and NF in test group B than the control. The drug Duovir-NTM is harmful to the cerebellum and should be prescribed with cytoprotective agents. () 2015 iGlobal Research and Publishing Foundation. All rights reserved.
\end{abstract}

\section{INTRODUCTION}

Duovir-N is a fixed dosed combination therapy used for the treatment of Human Immunodeficiency Virus; comprising of Lamivudine, zidovudine, nevirapine [1]. It is used to treat HIV patients who have already been on other HIV medications and have responded well to each of the drugs in the combination; and are also able to tolerate each of these medications, at the recommended doses without requiring a dose adjustment due to low weight. Duovir-N tablets prevent or slow down the ability of HIV to replicate and spread, which keeps the viral load down to a low level, allowing the numbers of CD4+ cells to increase so that the immune system can recover, reducing the risk of disease progression [2]. This triple drug therapy with Duovir-N makes it easier to take the medications regularly, which helps improve compliance and helps prevent resistance of HIV to individual drugs
[3]. Modern combination therapy is highly effective and people with HIV on antiretroviral treatment could live for the rest of their lives without developing AIDS [2].

Despite these improvements, prolonged benefits of antiretroviral drugs are compromised by numerous sideeffects, adverse clinical events and toxicities. All antiretroviral drugs can have both short-term and longterm adverse effects. The risk of specific side effects varies from drug to drug, from drug class to drug class and from patient to patient. Some of the clinical events include AIDS-related insulin resistance, lipodystropy syndrome, gastrointestinal symptoms, hyperglycemia [4$6]$. 


\section{Indo Global Journal of Pharmaceutical Sciences, 2015; 5(3): 210-215}

The most common and troublesome toxicities of Nucleoside Reverse Transcriptase Inhibitors (NRTIs) is hepatoxicity $[6,7]$. Virtually every licensed antiretroviral medication has been associated with liver enzyme elevations [8]. Liver toxicity may also occur as a consequence of mitochondrial damage in patients receiving nucleosides analogues, particularly Zidovudine or Stavudine $[9,10]$. Other detrimental effect of anti HIV drugs includes; allergies, hyperglycaemia, lactic acidosis, and gastrointestinal disorder [11], myelopathy, neuropathy, neurologic pain, changes in cognition and dementia [12].

In recent years through global collaboration lots of Nigerians are now taking antiretroviral therapy with its potential side effects $[13,14]$.The increase in conflicts in the country and consequent increase in rape has also increase the burden of people taking antiretroviral therapy as post exposure prophylaxis (PEP). Post exposure prophylaxis is also practiced by health workers when they have occupational exposure to HIV; they are expected to commence treatment within $72 \mathrm{hrs}$ after exposure and to continue with the medication for as long as 30 days. HIV positive pregnant women are also given this medication to prevent mother to child transmission of HIV thereby exposing the mother and the unborn child to this medication.

Prolong use of highly active antiretroviral therapy (HAART) can lead to neurologic complications, affecting neurobehavioral such as, myelopathy, neuropathy, neurologic pain, changes in cognition and dementia [13, 14]. There is a report that even low concentrations of antiretroviral (ARV) drugs that penetrate the blood brain barrier have detrimental effects on the central nervous system [15]. Cognitive impairment occur in a substantial (15-50\%) proportion of HIV infected patient on highly active antiretroviral therapy) [16-18]. It has also been reported that about $40 \%$ of patients treated with lamivudine develop toxicities related to the central nervous system, with symptoms such as dizziness, insomnia and depersonalization [19].

This study was designed to investigate the effects of administration of Duorvir-N on the histopathology of the cerebellum of Wistar rats.

\section{METHODOLOGY}

Twenty male Wistar rats were used for this study. The animals were acclimatized at the animal House of the College of Health Sciences University of Uyo for two weeks, before they were divided into 2 groups of 10 rats each. Group A served as the control, while group B were treated with $9.28 \mathrm{mg} / \mathrm{kg}$ of Duovir-N twice daily for 30 days. Douvir-N was from cipla pharmaceuticals and was obtained from the pharmacy of the University of Uyo Teaching Hospital, Uyo, Nigeria.

The animals were handled according to the guidelines for the treatment of laboratory animals and the study was approved by the ethical committee of the Graduate School Faculty of Basic Medical Sciences University of Uyo. The rats were treated for 30 days and allowed water and feed ad libitum. On the 31st day, the rats were sacrificed using chloroform inhalation method and their cerebellum harvested, processed and stained using the Haematoxylin and Eosin, Silver impregnated method, paraffin impregnated Glial Fibrilar Acidic Protein (GFAP) and Neurofilament (NF) immunochemistry methodS. Stained slides were viewed under a light microscope.

\section{RESULTS \& DISCUSSION}

The benefits of antiretroviral drugs are compromised by numerous side-effects, adverse clinical events and toxicities [20]. In this study there were clear distortions to the purkinje cells and granular cells of the cerebellum in the groups treated with Dourvir-N. This corroborated with earlier researches which reported that antiretroviral drugs may damage the cerebellum [21]. Cerebellum is known as a motor control centre, and it is increasingly recognized as contributing to general cognitive processing and emotional control [22-24]. However, findings have shown that the cerebellum may be able to perform cognitive activities independent of motor function [25, 26]. Studies on rats have associated HIV infection with increased neuronal degeneration and death $[27,28]$.This study has shown that in addition to the HIV infection the antiretroviral drug Dourvir-N might have the potential of causing neuronal degeneration. 


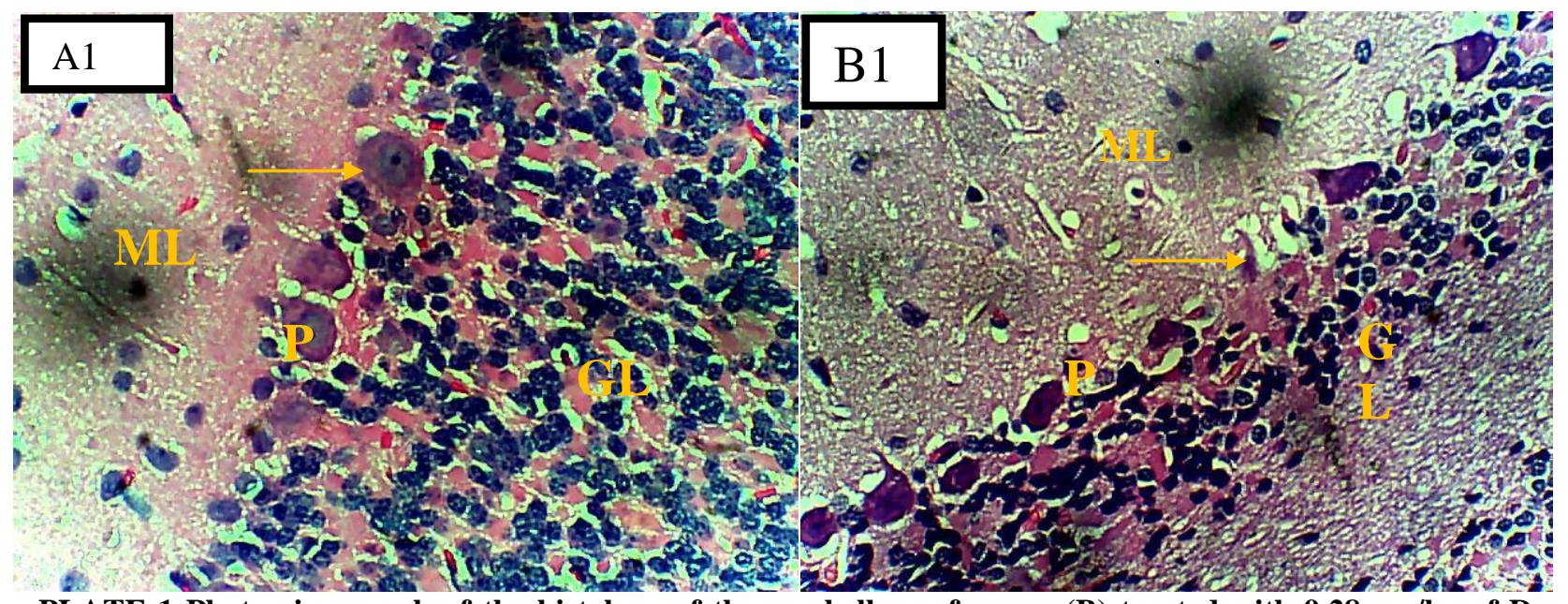

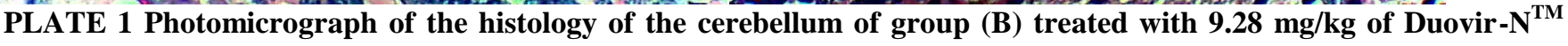
showed the three cerebellar cortical areas; molecular (ML) layer, granular (GL) layer, and disrupted and shrunken Purkinje (P) cells. The Purkinje cells appear elongated and aggregated. The granular cells appear aggregated when compared to control (A) H \& $\mathbf{E}, \times \mathbf{4 0 0}$.

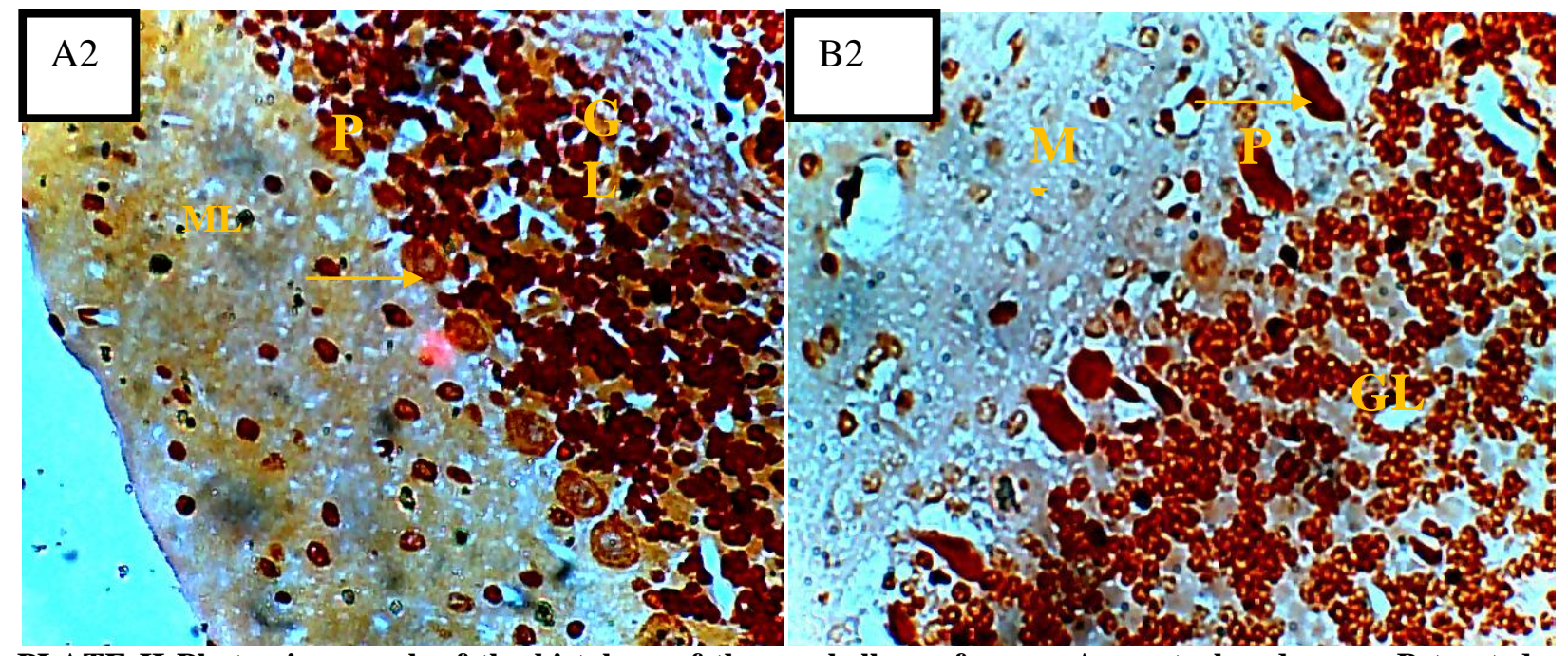

PLATE II Photomicrograph of the histology of the cerebellum of group A control and group B treated with 9.28 mg/kg of Duovir- $\mathrm{N}^{\mathrm{TM}}$ showed the three cerebellar cortical areas; molecular (ML) layer, granular (GL) layer, and disrupted and shrunken Purkinje (P) cells. The Purkinje cells appear elongated and the granular cells appear aggregated Silver stain, $\times \mathbf{4 0 0}$. 


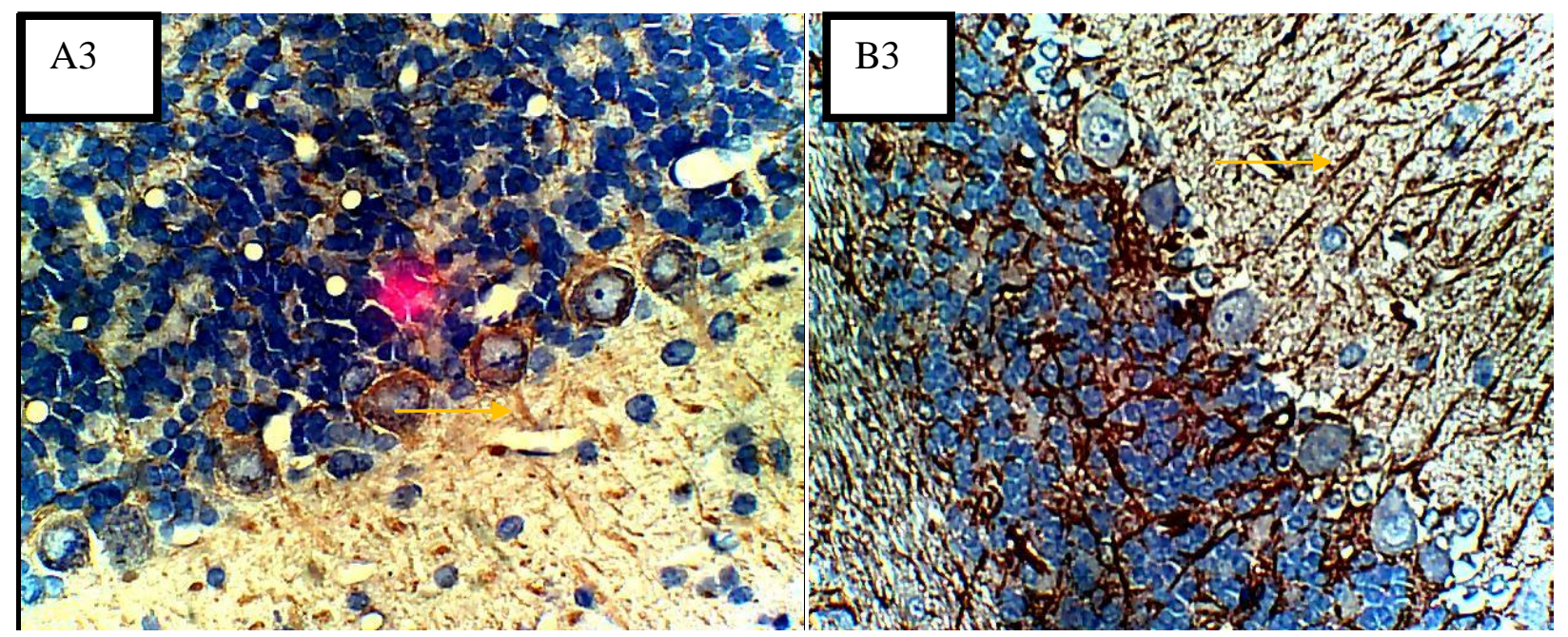

PLATE III Photomicrograph of the histology of the cerebellum of group A control and group B treated with 9.28 $\mathrm{mg} / \mathrm{kg}$ of Duovir-NTM showed severe increased expression of GFAP by astrocytes (arrow) in group B treated with Duovir-TM than the control group GFAP X 400

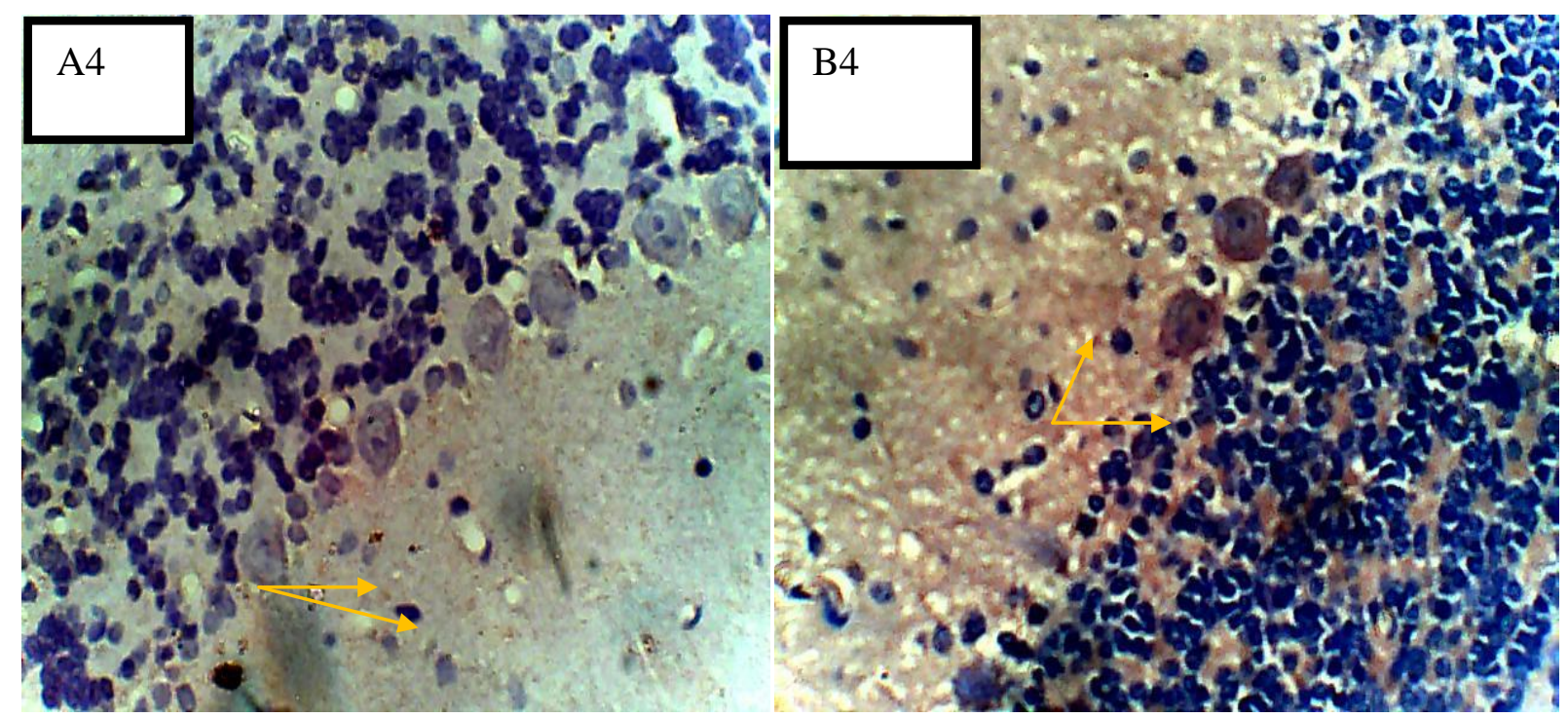

PLATE IV Photomicrograph of the histology of the cerebellum of group A control and group B treated with 9.28 $\mathrm{mg} / \mathrm{kg}$ of Duovir-NTM showed increased expression of NSE in group ( B) than the control group (A) NSE X 400 


\section{Indo Global Journal of Pharmaceutical Sciences, 2015; 5(3): 210-215}

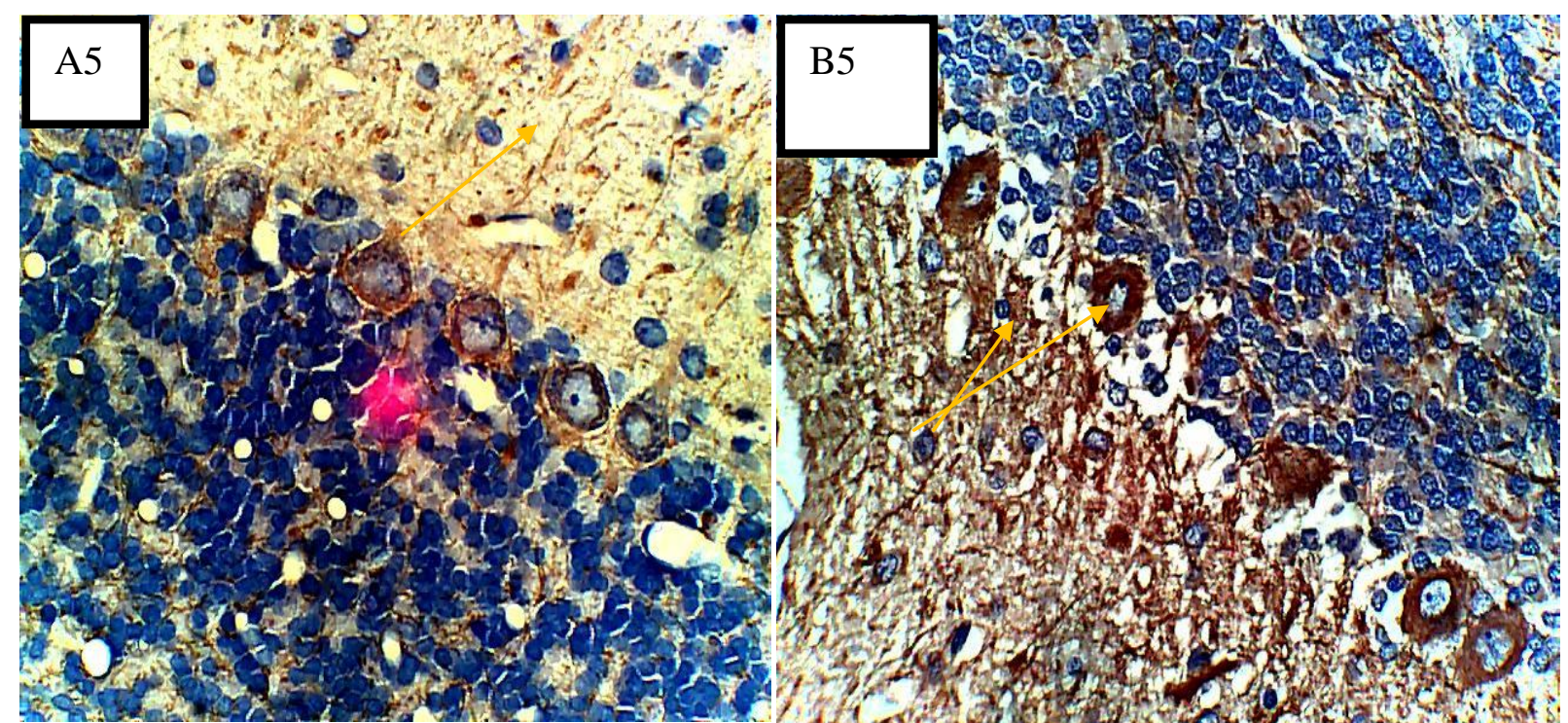

PLATE V Photomicrograph of the histology of the cerebellum of group A control and group B treated with 9.28 $\mathrm{mg} / \mathrm{kg}$ of Duovir-NTM showed increased expression of NF and more cellular population stained in group (B) treated with Duovir-NTM than the control group. NF X 400

TABLE 1 Color intensity of NSE, GFAP and NF between the control and Duovir-N group

\begin{tabular}{|c|c|c|c|}
\hline $\begin{array}{c}\text { N=10 } \\
\text { color intensity }\end{array}$ & NSE & GFAP & NF \\
\hline Control A & $*$ & $*$ & $*$ \\
\hline GROUP B & $* *$ & $* * *$ & $* * *$ \\
\hline
\end{tabular}

KEY: Mild * Moderate $* *$ Severe $* * *$

These findings were further supported by immunochemical studies which showed increased expression of GFAP by astrocytes and increased expression of NF by neurons in group B that was administered with Douvir-N. Glial fibrillary acidic protein is an astrocyte-specific intermediate filament protein whose expression is required for fibrous astrocyte normal function including maintenance of CNS white matter and blood-brain barrier integrity [29, 30]. Neurofilament and Neuron specific Enolase activity were up-regulated indicating neuronal damage in the groups treated with Douvir-N. The neurodegeneration and distortions in histological architecture might lead to motor dysfunction, this is of great concern to children and pregnant women who expose their unborn child to this drug.

\section{CONCLUSION}

This study has demonstrated that Douvir-N causes distortions in the histological appearance of the cerebellum. Routine neurologic assessment of patients on Douvir-N might help in early detection of cerebellar damage. Cytoprotective agents might be a necessary innovation in HIV treatment to reduce drug toxicity.

\section{REFERENCES}

[1]https://www.patientslikeme.com/treatment_evaluations/brows e/20908-douvirn-reviews? brand=f. Retrieved on line March 22nd, 2015

[2]http://www.aidsmeds.com/archive/PIs_1068.shtml. Retrieved online on June 7th 2014

[3]http://www.globalsources.com/si/AS/Parthweb-

Solutions/6008837110868/pdtl/Duovir-- N/1116459774.htm. Retrieved on line March 22nd, 2015

[4] Schambelan, M., Benson, C. and Carr, A. 2002. Acquired immune deficiency syndrome. Int. AIDS Soc. USA. Panel, 2002 ; 9: 30-32.

[5] http://www.indiamart.com/shivroyallifecare/cipla-hiv.html. Retrieved online on March 22nd, 2015

[6]http://aidsinfo.nih.gov/contentfiles/sideeffectanithivmeds_cbr ochure_en.pdf retrieved online on February 11th, 2015

[7] Sulkowski, M.S., Thomas, D.L., Mehta, S.H., Chaisson, R.E and Moore, D.R. Hepato-toxicity associated with nevirapine or efavirenz-containing antiretroviral therapy: Role of hepatitis C and B infections. Hepatology, 2002 ; 35: 182-189.

[8] Abrescia, N., M. D'Abbraccio, M. Figoni, A. Busto, A. Maddaloni and De Marco, M. Hepatotoxicity of antiretroviral drugs. Curr. Pharm. Des., . 2005 ; 11: 3697-3710. 


\section{Indo Global Journal of Pharmaceutical Sciences, 2015; 5(3): 210-215}

[9] Verucchi, G., L. et al. Ultrastructural liver mitochondrial abnormalities in $\mathrm{HIV} / \mathrm{HCV}$-coinfected patients receiving antiretroviral therapy. J. Acquired Immune Deficiency Syndromes, 2004 ; 35: 326-328.

[10] Walker, U. J. Depletion of mitochondrial DNA in liver under antiretroviral therapy with didanosine, stavudine, or zalcitabine. Hepatology, 2004 ; 39: 311-317

[11] Carr, A., Morey, A., Mallon, P., Williams, D., and Thorburn, D. R Fatal Portal

Hypertension, Liver Failure, and Mitochondrial Dysfunction after HIV-1 Nucleoside Analogue-Induced Hepatitis and Lactic Acidaemia. The Lancet, 2001 ; 357(9266) : 1412-1414.

[12] Glenn, J., Adam, I. Neurologic and Psychiatric Complications of Antiretroviral Agents. AIDS, 2002 ; 16:12011215.

[13] Treisman G. J and Kaplein A. I. Neurologic and Psychiatric Complication of Antiretroviral. AIDS. 2002 ; 16:1201-1215

[14] Tozzi, V. Balestra, P., Libertone, R. and Antinori, A. Cognitive function in treated HIV patients. Neurobehavioral HIV Medicine, 2010 ; 2: 95-113

[15] Heaton, R. K., et al., HIVassociated Neurocognitive Disorders Persist in the Era of Potent Antiretroviral Therapy: CHARTER Study. Neurology, 2010 ; 75:2087-2096

[16] Goodkin , K., Fletcher, M. A. and Cohen, N "Clinical aspects of psychoneuroimmunology," The Lancet, 1995; vol. 345 , no. 8943 , pp. $183-184$

[17] Xu, J. and Ikezu, T. The comorbidity of HIV-associated neurocognitive disorders and alzheimer's disease: a foreseeable medical challenge in post-HAART era," Journal of Neuroimmune Pharmacology, 2009 ; vol. 4, no. 2, pp. 200-212.

[18] Schouten, J., Cinque, P., Gisslen, M., Reiss, P. and Portegies P. Hiv-1 Infection and Cognition Impairment in Antiretroviral Era. Aids, 2011 ; 25(5): 561-575.

[19] Sewell, D. D. et al. HIV Associated Psychosis: A Study of Twenty Cases. San Diego HIV Neurobehavioural Research Centre Group. American Journal of Psychiatry, 1994 ; 151: 237 $-242$
[20] http://www.avert.org/antiretroviral-drugs-side-effects.htm Retrieved November10th, 2014.

[21] Peter, A. I., Ekanem, T. B., Ekong, M. B., Oguemedom, H.and Archibong A. M. Ameliorative Effects of Neurovite on histopathological Changes of the cerebellum of Lamuvidine Treated Wistar rats. Journal of Neurochemistry, 2013 ; 125(Suppl. 1):70.

[22] Gao, J. H. Parsons, L., Bower, M. J., Xiong, J. Li, J and Fox, P. T. Cerebellum implicated in sensory acquisition and discrimination rather than motor control, Science, 1996 ; vol. 272, no. 5261, pp. 545-547.

[23] Fiez, J. A. . Cerebellar contributions to cognition, Neuron, 1996 ; vol.16, no. 1, pp. 12-15,

[24] Chizhikov, V and Millen, K. J. Development and malformations of the cerebellum in mice, Molecular Genetics and Metabolism, 2003 ; vol. 80, no. 1-2, pp. 54-65.

[25] Schmahmann, J. D. Disorders of the cerebellum: ataxia, dysmetria of thought, and the cerebellar cognitive affective syndrome, Journal of Neuropsychiatry and Clinical Neurosciences, 2004 ; vol. 16, no. 3, pp. 367-378,

[26] Balsters, J.H., Whelan, C. D., Robertson, I. H and Ramnani, N. Cerebellumand cognition: evidence for the encoding of higher order rules, Cerebral Cortex, 2013 ; vol. 23, pp. 1433-1443.

[27] Lipton, S. A., and Gendelman, H. E. Dementia associated with the acquired immunodeficiency syndrome, The New England Journal of Medicine, 1995; vol. 332, no. 14, pp. 934940,

[28] Ellis, R. Langford, D and Masliah, E HIV and antiretroviral therapy in the brain: neuronal injury and repair, Nature Reviews Neuroscience, 2007; vol. 8, no. 1, pp. 33-44.

[29] Liedtke, W., et al. GFAP is Necessary for the Integrity of CNS White Matter Architecture and Long-term Maintenance of Myelination. Neuron, $1996 ; 17: 607-615$

[30] Kakinuma, Y. et al. Impaired Blood-brain Barrier Function in Angiotensinogen-deficient Mice. Nature Medicine, 1998 ; 4: $1078-1080$

Indo Global Journal of Pharmaceutical Sciences( ISSN 22491023 ; CODEN- IGJPAI; NLM ID: 101610675) indexed and abstracted in EMBASE(Elsevier), SCIRUS(Elsevier),CABI, CAB Abstracts, Chemical Abstract Services(CAS), American Chemical Society(ACS), Index Copernicus, EBSCO, DOAJ, Google Scholar and many more. For further details, visit 